RESEARCH PAPER

\title{
PRODUCTION OF COMPOSITE PELLETS FROM WASTE COFFEE GROUNDS, MILL SCALE AND WASTE PRIMARY BATTERY TO PRODUCE FERROMANGANESE; A ZERO WASTE APPROACH
}

\author{
Selçuk YEŞILTEPE ${ }^{l}$, Mustafa Kelami ŞEŞEN ${ }^{l}$ \\ Istanbul Technical University, Metallurgical and Materials Engineering Department, Maslak, Istanbul, Turkey
}

*Corresponding author: yesiltepes@itu.edu.tr, tel.: +90 212285 7061, Istanbul Technical University, Metallurgical and Materials Engineering Department, Turkey.

Received: 07.05.2020

Accepted: 26.05 .2020

\begin{abstract}
This study was aimed to produce ferromanganese by using waste battery as manganese source, mill scale as iron source and waste coffee ground as reduction agent and carbon source. Waste batteries were collected from waste battery collection bins. Mill scale was collected from hot rolling workshop. Waste coffee grounds were household used coffee. All starting materials were characterized. Weighted raw materials blended with addition of bentonite as a binder. Pelletizing equipment was used to produce composite pellets. Produced pellets were dried then used for reduction experiments. Reduction experiments were conducted in Argon purged tube furnace for $1250{ }^{\circ} \mathrm{C}, 1300{ }^{\circ} \mathrm{C}$ and $1400{ }^{\circ} \mathrm{C}$ according to thermodynamic background. Produced ferromanganese samples were characterized for chemical compositions and metallization rate.
\end{abstract}

Keywords: waste battery, pelletizing, mill scale, waste coffee, recycling, zero waste.

\section{INTRODUCTION}

Waste management is gaining importance because of depleting natural resources. Increasing consumption of materials with increasing population gained popularity to recycling and material recovery technologies. Energy efficiency is another important issue in recycling operations. Recycling of a material decreases the energy consumption by cutting off raw material preparing steps in production. Waste battery is considered as a hazardous waste because of acidic or basic electrolyte in the battery system [1]. Primary batteries or in other words single use batteries are designed for one time using with irreversible chemical reactions to produce electrical current [2]. There are different types of batteries with different ingredients, the most known and used primary battery composition is $\mathrm{ZnO}-\mathrm{MnO}_{2}$ with option of alkaline and $\mathrm{Zn}-\mathrm{C}$ varieties [3]. The difference between $\mathrm{Zn}-\mathrm{C}$ and alkaline batteries is used electrolyte. $\mathrm{Zn}-\mathrm{C}$ batteries uses $\mathrm{ZnCl}_{2}$ as electrolyte while alkaline battery uses $\mathrm{KOH}$ [4]. Cathode and anode structures are similar in both battery types [2]. Recycling of single use batteries studied from different researchers with different methods. General approach for recycling single use batteries is pyrometallurgical method because of fast and efficient process [3]. Primary waste battery recycling consists of reduction evaporation of $\mathrm{Zn}$ at first step followed by total or partial reduction of manganese oxides to produce various manganese based chemicals or alloys [5, 6]. High vapour pressure of $\mathrm{Zn}$ at relatively low temperatures to $\mathrm{Mn}$ available the vaporization - condensation route for $\mathrm{Zn}$ recovery in battery recycling [6]. Vacuum applied processes can be applied to decrease $\mathrm{Zn}$ evaporation temperature $[6,7]$. After $\mathrm{Zn}$ recovery batteries can be used as Mn raw material and generally considered for ferromanganese production $[3,6]$.

Waste coffee grounds are evaluated in various recycling applications due to large amount of waste [8]. Coffee is the second most used trading good after petroleum worldwide [9]. Waste coffee grounds are used with and without treatment in various applications. Waste coffee grounds are valorized to produce carbon based materials generally [8, 10, 11]. Active carbon [12], pharmaceutical compounds [11], biodiesel [10], anode material [13] are produced via valorization of waste coffee grounds. Chemical treatment is applied to waste coffee grounds to refine unwanted compounds in order to obtain desired products without using valorization in different applications [14, 15]. Large consumption amounts and accessible waste stream worldwide, offers different recycling or reusing opportunity to waste coffee grounds.

Hot rolling process is applied to steel slabs in order to produce thinner steel sheet. Mill scale is the lost material from steel slab due to oxidation at annealing step of hot rolling [16]. Mill scale is consists of oxides of elements in steel which is Fe in large portions. Recycling of mill scale is generally reuse of material in steelmaking process as an iron source [17]. Mill scale can be used in production of iron based materials as well[18]. Mill scale contains high iron amount thus can be evaluated as raw material for steel producing instead of blending in other resources[19], [20]. Recycling of mill scale and other steelmaking dusts requires pre-treatment of sample in order to use in conventional steelmaking process. Agglomeration is applied to iron containing dusts due to small particle size that restricts use in blast furnace operation [16,17-21-23]. Pelletizing can be used as an agglomeration process in the recycling of mill scale.

This study is aimed to produce ferromanganese with using waste coffee grounds as a reductive carbon source, waste battery paste as manganese source and mill scale for iron source. Pelletizing process is applied to produce composite pellets for reduction. Reduction of pellets is conducted in controlled atmosphere tube furnace. Characterization of starting materials and end product is done.

\section{MATERIAL AND METHODS}

\section{Raw Materials}

Waste coffee grounds are collected from household wastes. Collected waste coffee grounds are washed with distilled water and dried at $105{ }^{\circ} \mathrm{C}$ for 24 hours. DTA-TG analysis of waste coffee grounds is applied to sample of $1 \mathrm{mg}$. Waste battery is obtained from municipal battery collection points. Waste batteries are shredded; steel casing and battery paste is separated. Chemical analysis of battery paste is done with standard procedure of Atomic Absorption Spectroscopy. The battery paste is washed with distilled water to wash out the battery electrolyte. Mill scale is chemically analyzed with AAS and XRD technique is used to determine phases of oxides. Further explanation of characterization results of raw materials are discussed in Results. Blend composition is given in Table 1. Bentonite that used in pelletizing process as binder is Na-based bentonite obtained from Tokat-Turkey. Chemical composition of Na-bentonite is analyzed with AAS and phases are determined by X-ray analysis.

Table 1. Blend composition of pelletizing raw materials.

\begin{tabular}{ll}
\hline Element & \% \\
\hline $\mathrm{Zn}$ & 14.4 \\
$\mathrm{Mn}$ & 20.3 \\
$\mathrm{Fe}$ & 20.19 \\
$\mathrm{C}$ & 4.3 \\
Bentonite & 2.0 \\
Oxides & 38.81 \\
\hline
\end{tabular}

\section{Pelletizing}

Pelletizing of raw materials is done to produce composite ferromanganese pellets. Total $1500 \mathrm{~g}$ of blend is used. Materials are calculated to have $150 \%$ excess carbon with $\mathrm{Fe} / \mathrm{Mn}$ ratio of 1:1. Raw materials are blended with Na-bentonite of 
$\% 2$ wt. as binder. Laboratory scale pelletizing disc of $50 \mathrm{~cm}$ diameter is used with $40 \mathrm{rpm}$ rotational speed. Agglomeration of blended dust is obtained by manual water spraying. Produced pellets are tested for free fall test for elasticity determination. Water spraying of pellets continued until free fall number of 3 is obtained. Produced pellets are dried at $105{ }^{\circ} \mathrm{C}$ for 24 hours before firing/reducing in Argon purged tube furnace.

\section{Thermodynamic Calculations}

Reduction of metallic oxides by carbon is the general practice for many manufacturing process. Production of ferromanganese needs extensive $\mathrm{CO}$ partial pressure for reduction of $\mathrm{MnO}$ [24]. $\mathrm{CO}$ is produced in reduction systems via Boudouard reaction. Boudouard reaction is the basis of carbothermic reduction system. Boudouard reaction is given as;

$$
2 \mathrm{CO} \leftrightarrow \mathrm{C}+\mathrm{CO}_{2}
$$

$\mathrm{CO}$ is produced or consumed in the reduction system according to equilibrium of Boudouard reaction. $\mathrm{CO}$ is more stable at elevated temperatures than $\mathrm{CO}_{2}$. Due to this thermodynamic background reduction reactions are expected to start with solid $\mathrm{C}$ then proceed to $\mathrm{CO}$ gas-solid reactions.

Free energy calculations for reduction of $\mathrm{Zn}, \mathrm{Fe}$ and $\mathrm{Mn}$ oxides are done with HSC 6.1 thermodynamic database. Gibbs free energy of oxides along with $\mathrm{CO}$ and $\mathrm{CO}_{2}$ are given in Figure 1. Ellingham diagram shows reduction of $\mathrm{FeO}$ occurs below $800{ }^{\circ} \mathrm{C}$ while $\mathrm{ZnO}$ carbothermal reduction is about $950{ }^{\circ} \mathrm{C} . \mathrm{MnO}$ reduction with $\mathrm{CO}$ occurs at the temperature of $1400{ }^{\circ} \mathrm{C}$. $\mathrm{MnO}$ can be reduced by $\mathrm{Mn}$ or Fe carbides formed in system. High solubility of Fe and $\mathrm{Mn}$ in each other at high temperatures can decrease the activation energy need in $\mathrm{MnO}$ reduction. $\mathrm{kcal} / \mathrm{mol}$ Delta G (Ellingham)

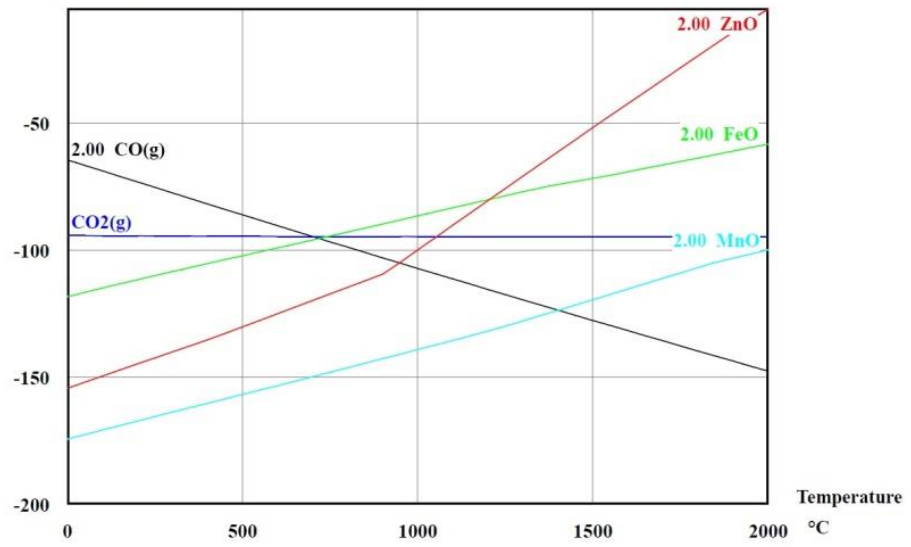

Fig 1. Ellingham diagram of $\mathrm{Zn}, \mathrm{Fe}, \mathrm{Mn}$ oxides with $\mathrm{CO}$ and $\mathrm{CO}$.

Ellingham diagram shows reduction conditions for metal oxides in the system. Reduction reactions of $\mathrm{ZnO}$ and $\mathrm{MnO}$ are expected to take place in $\mathrm{CO}$ atmosphere. On the other hand, $\mathrm{FeO}$ carbothermic reduction is at the equilibrium temperature of the Boudouard reaction. That means $\mathrm{FeO}$ can be reduced via both $\mathrm{C}$ and $\mathrm{CO}$ or in other words direct and indirect reaction take place in $\mathrm{FeO}$ reduction simultaneously. Reduction reactions of metal oxides are given as;

$$
\begin{gathered}
\mathrm{MnO}+\mathrm{CO}=\mathrm{Mn}+\mathrm{CO}_{2} \\
\mathrm{ZnO}+\mathrm{CO}=\mathrm{Zn}+\mathrm{CO}_{2} \\
\mathrm{FeO}+\mathrm{CO}=\mathrm{Fe}+\mathrm{CO}_{2} \\
\mathrm{FeO}+\mathrm{C}=\mathrm{Fe}+\mathrm{CO}
\end{gathered}
$$

\section{Reduction Process}

Reduction roasting process is proposed based on thermodynamic calculations and literature knowledge. Proposed flow diagram of process is given in Figure 2. Raw materials of waste coffee grounds, mill scale and waste battery paste are blended with bentonite powder. Blend is pelletized with water addition in laboratory scale pelletizing disc with diameter of $50 \mathrm{~cm}$. Pellets are dried then direct reduced in Argon purged $(1 \mathrm{lt} / \mathrm{min})$ tube furnace at 1250,1300 and $1400{ }^{\circ} \mathrm{C}$. Chemical analysis of pellets is conducted with Atomic Absorption Spectroscopy. Condensed $\mathrm{ZnO}$ is found in furnace exit. $\mathrm{ZnO}$ could not be collected in experiments due to lack of facilities for condensation chamber.

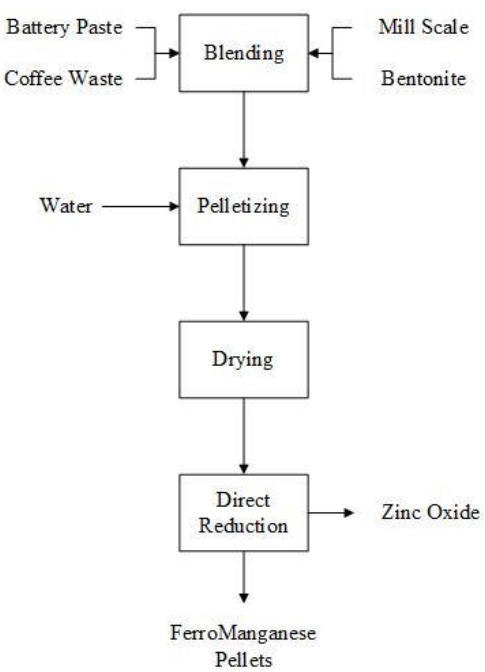

Fig 2. Flow sheet of process.

\section{Characterization Methods}

Raw materials are analyzed with Atomic Absorption Spectroscopy techniques via Perkin Elmer Analyst 800. All of raw materials are leached with aqua regia solution at $110{ }^{\circ} \mathrm{C}$ on hot plate for 30 minutes. Solution is analyzed via AAS with standard protocol. XRD analysis' of materials are conducted with PANalytical PW 3040/60 using $\mathrm{Cu} \mathrm{K \alpha}$ radiation $(\lambda=0.154 \mathrm{~nm})$. DTA-TG analysis is conducted with Perkin Elmer Diamond under Ar flow at temperature increase rate of $5{ }^{\circ} \mathrm{C} / \mathrm{min}$. Pellet free fall number is determined by free fall of pellets from $50 \mathrm{~cm}$ of height until crack occurs. Moisture content of pellets is determined by placing in incubator at $105{ }^{\circ} \mathrm{C}$ for 24 hours then measuring the weight difference. Pelletizing efficiency is calculated with formulae;

$$
\text { Efficiency } \%=\frac{\text { Acceptable Pellets }(9-16 \mathrm{~mm})}{\text { Initial Mass of Blend }} \times 100
$$

Pellets are sieved manually after pelletizing and pellets in the range of $9-16 \mathrm{~mm}$ are accepted as green pellets. Efficiency of $\mathrm{Zn}$ removal, Fe metallization and $\mathrm{Mn}$ metallization are calculated with formulae;

$$
\text { Efficiency } \%=\frac{\text { Reduced Mass }}{\text { Initial Mass }} \times 100
$$

\section{RESULTS AND DISCUSSION}

Raw materials are characterized with techniques mentioned in Experimental Materials and Methods section. DTA-TG analysis of coffee grounds is given in Figure 3. Coffee ground is analyzed and pyrolysis occurred under Argon atmosphere. Stable carbon is found to be in left over mass after gasification in DTA-TG analysis. Stable carbon amount is $18.5 \%$ in used spent ground coffee waste. Pyrolysis process of spent ground coffee starts in $300{ }^{\circ} \mathrm{C}$ and finishes about $500{ }^{\circ} \mathrm{C}$. Mass loss of spent ground coffee waste continues with higher temperature exposure but to a limited extend. $18.5 \%$ of spent ground coffee waste is taken into account in calculations for reductive carbon source.

Pyrolysis of waste coffee grounds produces reduction agent of carbon in the pellets. Carbothermal reduction of zinc, iron and manganese oxides requires high energy and CO partial pressure [6, 24]. Pyrolysis and reduction process takes place simultaneously in the reduction vessel. Thermodynamic calculations along with DTA/TG analysis can be concluded into that pyrolysis is followed by reduction reaction. 


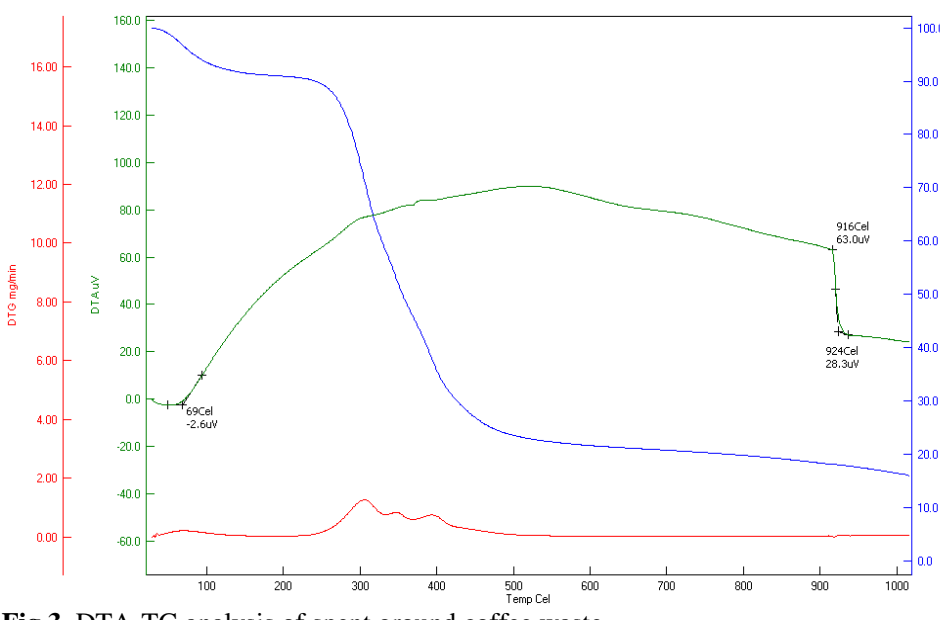

Fig 3. DTA-TG analysis of spent ground coffee waste.

Chemical composition of washed, dried waste battery is given in Table 2. Waste battery paste is rich in manganese and zinc oxides. Alkaline based electrolyte in alkaline batteries is the cause of $\mathrm{K}$ in battery paste. Manganese is evaluated is main manganese source for ferromanganese production. Zinc is planned to be evaporated and condensed as zinc oxide in furnace.

Table 2. Chemical analysis of spent battery paste.

\begin{tabular}{ll}
\hline Element & \% \\
\hline $\mathrm{Zn}$ & 29.1 \\
$\mathrm{Mn}$ & 40.37 \\
$\mathrm{~K}$ & 2.32 \\
$\mathrm{Fe}$ & 1.35 \\
$\mathrm{~Pb}$ & 0.0018 \\
Loss of Ignition & 26.96 \\
\hline
\end{tabular}

Mill scale chemical analysis and XRD analysis is given in Table 3 and Figure 4 consecutively. Main compound in mill scale is iron and iron oxides. Mill scale is collected from hot rolling workshop. Chemical composition of mill scale represents original chemical composition of steel slab in oxide form. Table 3 shows large amount of iron without excessive alloying elements.

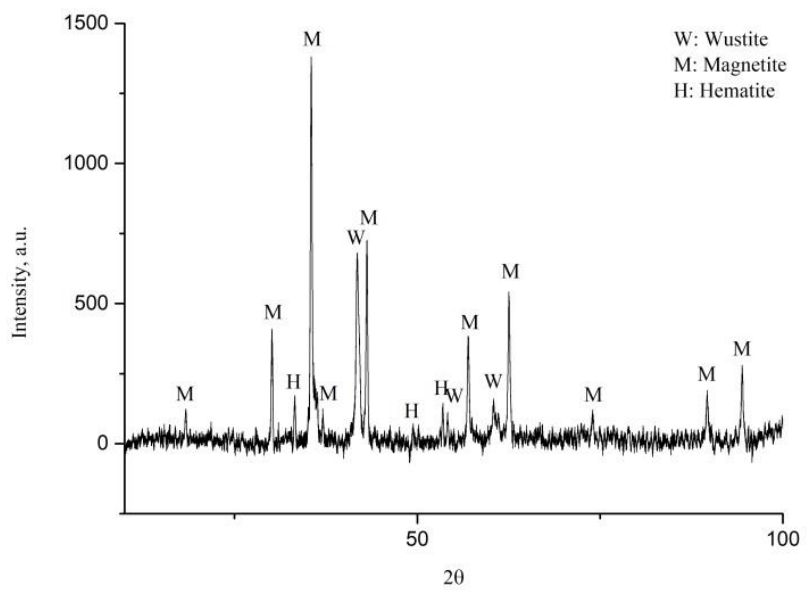

Fig 4. XRD pattern of mill scale.
Table 3. Chemical analysis of mill scale.

\begin{tabular}{ll}
\hline Compound & $\%$ \\
\hline Iron Oxides(total) & 98.33 \\
$\mathrm{MnO}$ & 0.58 \\
$\mathrm{SiO}_{2}$ & 0.21 \\
$\mathrm{Cu}_{2} \mathbf{O}$ & 0.24 \\
$\mathrm{Cr}_{2} \mathrm{O}_{3}$ & 0.29 \\
Others & 0.35 \\
\hline
\end{tabular}

Na-bentonite chemical analysis is given in Table 4. Bentonite consists of aluminum calcium silicates with addition of $\mathrm{Na}_{2} \mathrm{O}$. Relatively higher $\mathrm{Na}_{2} \mathrm{O}$ level of bentonite is the cause of Na-bentonite naming.

Table 4. Chemical analysis of bentonite.

\begin{tabular}{ll}
\hline Compound & \% \\
\hline $\mathrm{SiO}_{2}$ & 52.70 \\
$\mathrm{Al}_{2} \mathbf{O}_{3}$ & 20.40 \\
$\mathbf{F e}_{2} \mathbf{O}_{3}$ & 5.17 \\
$\mathbf{C a O}$ & 4.86 \\
$\mathbf{M g O}$ & 1.83 \\
$\mathbf{K}_{2} \mathbf{O}$ & 1.10 \\
$\mathrm{Na}_{2} \mathbf{O}$ & 2.75 \\
$\mathbf{L O I}$ & 11.19 \\
\hline
\end{tabular}

LOI: Loss Of Ignition

Pelletizing experiment results are collected in three subjects; pelletizing efficiency, free fall test and moisture content. All results are given in Table 5. Free fall numbers and moisture content of green pellets meet the green pellet requirements for pelletizing. Efficiency of pelletizing process is adequate to consider the process feasible.

Table 5. Green pellet properties.

\begin{tabular}{ll}
\hline Property & Result \\
\hline Free Fall Mean Number & 3 \\
Moisture Content & $10.44 \%$ \\
Pelletizing Efficiency & $91.18 \%$ \\
\hline
\end{tabular}

Metallization rate of iron and manganese is calculated after reduction experiments. Produced ferromanganese alloy is characterized with AAS technique. Zinc is evaporated from reaction chamber and zinc evaporation rate is calculated with leftover zinc in ferromanganese. Results of ferromanganese chemical analysis are given in Table 6. Metallization rate is visualized in Figure 5 . The produced ferromanganese alloy is low in manganese than calculated value. This result shows that the alloy cannot be considered as ferromanganese but a master alloy in ferromanganese production.

Use of waste coffee grounds as reducing agent in composite pellets is efficient in reduction of manganese, iron and zinc oxides. Pyrolysis of waste coffee grounds produces amorphous carbon skeleton of coffee grain with high surface area [13]. High surface area, direct contact of reagents eases the reduction process. Reagent contact and short diffusion pathway for reducing gases helps the reduction process. Reduction temperature of the pellets is lower than thermodynamic calculated reduction point nevertheless metallization of $70 \%$ in manganese was achieved in this study. XRD analysis of pellets that reduced at $1400{ }^{\circ} \mathrm{C}$ conducted to understand what is produced. XRD results explains low metallization rate of manganese. $\mathrm{MnO}$ peaks are exhibited along with manganese peaks while the rest is cementite $\left(\mathrm{Fe}_{3} \mathrm{C}\right)$. Thermodynamic background supports this result that $\mathrm{MnO}$ needs high $\mathrm{CO}$ pressure and high temperature to be reduced [24]. Further reduction of $\mathrm{MnO}$ needs higher $\mathrm{CO}$ partial pressure hence approximately $29 \%$ $\mathrm{Mn}$ left in $\mathrm{MnO}$ form. Increasing the reduction rate of $\mathrm{MnO}$ can be achieved by increasing the temperature or CO partial pressure. XRD result of reduced pellets is given in Figure 6

Table 6. Chemical analysis of Ferromanganese.

\begin{tabular}{llll}
\hline Element & $\mathbf{\% , 1 2 5 0} \mathbf{~}^{\mathbf{C}}$ & $\mathbf{\% , 1 3 0 0}{ }^{\mathbf{0}} \mathbf{C}$ & $\mathbf{\% , 1 4 0 0}{ }^{\mathbf{O}} \mathbf{C}$ \\
\hline $\mathrm{Fe}$ & 44.8 & 46.6 & 49.1 \\
$\mathrm{Mn}$ & 34.7 & 35.6 & 35.7 \\
$\mathrm{Zn}$ & 0.032 & 0.015 & 0.014 \\
Others & Balance & Balance & Balance \\
\hline
\end{tabular}




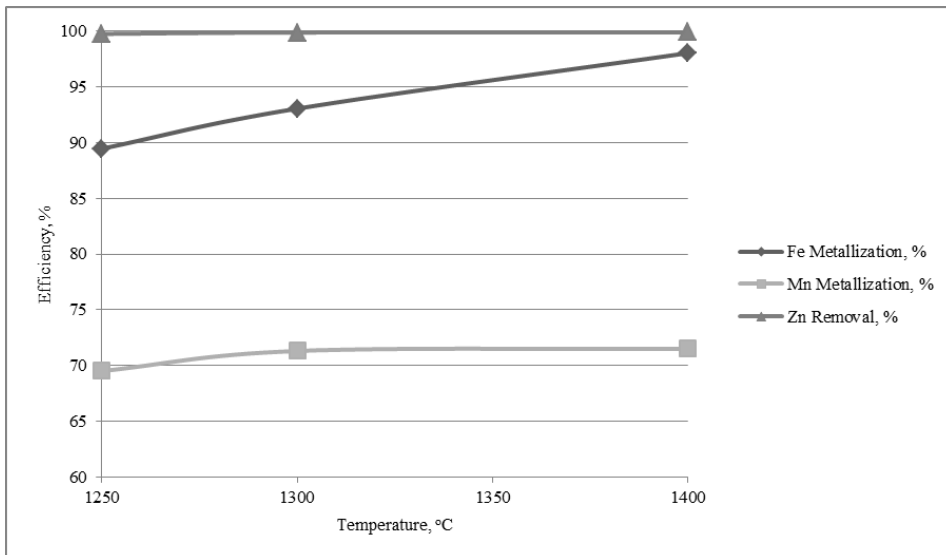

Fig 5. Fe and Mn metallization rate with $\mathrm{Zn}$ removal rate.

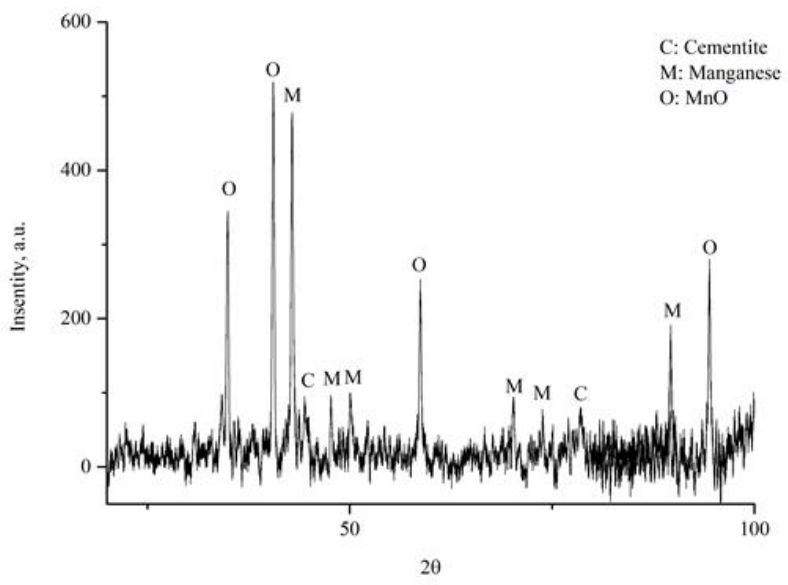

Fig 6. XRD analysis of reduced pellet at $1400{ }^{\circ} \mathrm{C}$.

\section{Conclusion}

Pelletizing of waste coffee grounds, waste battery paste and mill scale is a promising solution for recycling of these wastes. The produced pellets have sufficient properties for producing ferromanganese. Pelletizing process efficiency is calculated $91.18 \%$ which can be evaluated as successful. This process can utilize three different waste into two useful products; ferromanganese and zinc oxide. Waste batteries are classified as hazardous waste and by this process it can be turned into a useful product. Pelletizing process and solid state reaction ease the operation of waste utilization. Zinc oxide on the other hand can be evaluated in producing zinc metal or various compounds. The wastes are totally converted into useful products and economical value is obtained.

\section{References}

1. Yeşiltepe S, Sesen MK (2019) Battery Collection in Turkey, Case Study of Küçükçekmece Municipality. J. Int. Environmental Application \& Science, 14:116-121.

2. Espinosa DCR, Mansur MB (2012) Recycling batteries. Waste Electr Electron Equip Handb 365-384. https://doi.org/10.1533/9780857096333.3.365.

3. Bernardes AM, Espinosa DCR, Tenório JAS (2004) Recycling of batteries: A review of current processes and technologies. J Power Sources 130:291-298. https://doi.org/10.1016/j.jpowsour.2003.12.026.

4. Gallegos M V., Falco LR, Peluso MA, et al (2013) Recovery of manganese oxides from spent alkaline and zinc-carbon batteries. An application as catalysts for VOCs elimination. Waste Manag. 33:1483-1490.

https://doi.org/10.1016/j.wasman.2013.03.006.
5. Ebin B, Petranikova M, Steenari BM, Ekberg C (2016) Production of zinc and manganese oxide particles by pyrolysis of alkaline and $\mathrm{Zn}-\mathrm{C}$ battery waste. Waste Manag 51:157-167. https://doi.org/10.1016/j.wasman.2015.10.029.

6. Yeşiltepe S, Buğdaycı M, Yücel O, Şeşen MK (2019) Recycling of alkaline batteries via a carbothermal reduction process. Batteries 5: https://doi.org/10.3390/batteries5010035.

7. Saotome Y, Nakazawa Y, Yamada Y (1999) Disassembling and materials recovering process of alkaline manganese dry batteries by vacuum-aided recycling systems technology (VARS Tech.). Vacuum 53:101-104. https://doi.org/10.1016/S0042-207X(98)00401-1.

8. Kovalcik A, Obruca S, Marova I (2018) Valorization of spent coffee grounds: A review. Food Bioprod Process 110:104-119. https://doi.org/10.1016/j.fbp.2018.05.002.

9. Chung CC, Chen ST, Chen YY, Chung CY (2014) The empirical study for national determinant of coffee consumption. Adv Mater Res 962-965:12751278. https://doi.org/10.4028/www.scientific.net/AMR.962-965.1275.

10. Caetano NS, Caldeira D, Martins AA, Mata TM (2017) Valorisation of Spent Coffee Grounds: Production of Biodiesel via Enzymatic Catalysis with Ethanol and a Co-solvent. Waste and Biomass Valorization 8:1981-1994. https://doi.org/10.1007/s12649-016-9790-z.

11. Mata TM, Martins AA, Caetano NS (2018) Bio-refinery approach for spent coffee grounds valorization. Bioresour Technol 247:1077-1084. https://doi.org/10.1016/j.biortech.2017.09.106.

12. Hernández Rodiguez M, Yperman J, Carleer R, et al (2018) Adsorption of $\mathrm{Ni}(\mathrm{II})$ on spent coffee and coffee husk based activated carbon. J Environ Chem Eng 6:1161-1170. https://doi.org/10.1016/j.jece.2017.12.045.

13. Gao G, Cheong L-Z, Wang D, Shen C (2018) Pyrolytic carbon derived from spent coffee grounds as anode for sodium-ion batteries. Carbon Resour Convers 1:104-108. https://doi.org/10.1016/j.crcon.2018.04.001.

14. Li RX, Shen XL, Zhou Y, et al (2016) Preparation and properties of polyurethane films with spent coffee grounds. Mater Sci Forum 848:148-151. https://doi.org/10.4028/www.scientific.net/MSF.848.148.

15. Zuorro A, Lavecchia R (2013) Preparation and characterization of magnetically responsive biosorbents from coffee industry residues. Appl Mech Mater 394:3-7. https://doi.org/10.4028/www.scientific.net/AMM.394.3.

16. Chen L (2013) Utilization of steelmaking and hot-rolling mill waste. Appl Mech Mater 261-262:627-630.

https://doi.org/10.4028/www.scientific.net/AMM.260-261.627.

17. Zhang J, Liu S, Niu F, Xu Z (2013) Reviews on the comprehensive utilization of metallurgical dust from iron and steel plant. Appl Mech Mater 295298:3075-3079. https://doi.org/10.4028/www.scientific.net/AMM.295-298.3075. 18. Bugdayci M., Alkan M., and Turan A. (2018) Production of Iron Based Alloys from Mill Scale through Metallothermic Reduction. High Temp. Mater. Proc. 37(9-10): 889-898. https://doi.org/10.1515/htmp-2017-0073.

19. Gaballah N.M., Zikry A.F., Khalifa M.G., Farag A.B., and Shalabi M.E.H. (2013) Production of Iron from Mill Scale Industrial Waste via Hydrogen, Open J Inorg. Non-Metall Mater. 2013: 23-28. http://dx.doi.org/10.4236/ojinm.2013.33005.

20. Martín MI, López FA \& Torralba JM (2012) Production of sponge iron powder by reduction of rolling mill scale, Ironmaking \& Steelmaking, 39:3, 155162, https://doi.org/10.1179/1743281211Y.0000000078.

21. Maalem B, Berdjane D, Belahssen O, et al (2019) Identification of thermal and microstructural properties of hot rolling scale. Acta Metall Slovaca 25:291296. https://doi.org/10.12776/ams.v25i4.1360.

22. Drobíková K, Plachá D, Motyka O, et al (2016) Recycling of blast furnace sludge by briquetting with starch binder: Waste gas from thermal treatment utilizable as a fuel. Waste Manag 48:471-477.

https://doi.org/10.1016/j.wasman.2015.11.047.

23. Li XB, Wang W, Zhang DH, Xiong L (2014) Basic properties of iron and steel making dust. Adv Mater Res 937:187-190. https://doi.org/10.4028/www.scientific.net/AMR.937.187.

24. Sesen FE (2017) Practical reduction of manganese oxide. J Chem Technol Appl 01:1-3. https://doi.org/10.35841/chemical-technology.1.1.26-27. 